\title{
Domestic Violence: A Social Issue in Rural Tripura
}

\author{
Jayanta Choudhury, Moutoshi Deb \\ Department of Rural Management and Development, Tripura University, Tripura, India \\ Email: debmoutoshi2015@gmail.com
}

Received 3 August 2015; accepted 25 October 2015; published 29 October 2015

Copyright (C) 2015 by authors and Scientific Research Publishing Inc.

This work is licensed under the Creative Commons Attribution International License (CC BY). http://creativecommons.org/licenses/by/4.0/

(c) $\underset{\mathrm{EY}}{\mathrm{B}}$ Open Access

\begin{abstract}
Domestic violence is a wide spread problem, its actual extent is difficult to measure. According to available statistics throughout the world, about 33 percent women have experienced violence at some point of their life (WHO, 1997). In India, women form about half of the population and enjoy various freedom and rights but simultaneously, like other developing countries, violence against women is overwhelming and is a matter of concern. Domestic violence leads to violence of human rights and prevents them from enjoying their fundamental rights. Though the types of violence differs from society to society, nations to nations, religion to religion, but it prevails in underdeveloped, developing and developed countries, too. Domestic violence refers to "assaultive and coercive behaviours that adults use against their intimate partners" (Holden, 2003). In India, there are a set of well equipped legislations which protect women against violence. And Protection of Women against Domestic Violence Act, 2005 is the milestone in the history of legal control and judicial response in domestic violence affairs. But the rate of violence against women increased 44 percent during 1993 to 2011. The findings of the paper are expected to enlighten individuals and the community on the causes and consequences of violence against women. The paper comes out with policy prescription for government and non-government organizations towards addressing the problem.
\end{abstract}

\section{Keywords}

Violence, Women, Rural, Human Right, Fundamental Right

\section{Introduction}

A society is composed of many institutions and the most important of them are the system of decent, family and kinship, marriage and religious traditions. They provide the ideology and moral basis for men and women about their rights and duties and their status and role (Narasimhamurthy, 2014). 
Violence against women is not only national or regional issue; nowadays it is increasing day by day and evolves out as global burning social issue. Domestic violence is a problem affecting millions of women globally and this problem manifests in various forms, for instance, in the context of marriage or cohabitation, between siblings and between parents and their children (Lynn, 2004). The NFHS-III report reveals that 37 percent married women in India are the victims of physical and sexual abuse by their husband (International Institute for Population Sciences, 2007).

However, many feminist researchers have pointed out that domestic violence is a gender neutral term and as such fails to clarify who is the victim and who is the perpetrator, making the fact that in many relationships women are most frequently subjected to violence by men (Brodsky \& Hare-Mustin, 1980). Coomarswamy (2005) and Mukherjee et al. (2001) analyzed the official statistics pertaining to crimes against women in India. They have the view that many of the crimes against women go unreported.

There are several causes of sexual as well as moral abuse which are very often highlighted by the media in Indian modern society, and a lot of those also remain unexplored. Although, such violence against women, sexual harassment, and exploitation to women is not of recent origin, its trace is found in the history of ancient India. According to the federal Bureau of Investigation of the USA, about 2 million men per year beat their partners.

Violence against women is a worldwide problem as well as in India. According to UN Press, report two-thirds of married Indian women are victims of domestic violence. Seventy percent of married Indian women between the ages of fifteen and forty-nine were proven victims of ugly incidences like rape, beating, forced or coerced sex and each incident of domestic violence led to the loss of seven working days for a woman in a country like India (United Nation Population Fund Report).

Violence against women is a serious problem in India as well as in Tripura. Overall the women aged 15 - 49 have experienced physical violence in India. The percentage of domestic violence that is pervasive in India rural area is 42.9and urban areas is 32.7. According to National Family Health Survey-III, 37.2 percentage Indian married women have experienced violence and abused by their spouse.

Domestic violence includes a range of behaviours like physical, sexual, economic, emotional and psychological abuse which directed towards establishing and maintaining power and control over an intimate partner. The societal tendency to blame domestic violence victims and excused perpetrators is rooted in a history of cultural and legal traditions that have supported the domination and abuse of women by men in intimate relationships. Despite greater public awareness, however, myths and misconceptions about battered women's experiences persist. Interventions based on these myths can have a devastating effect on victims and their families (Singh, 2013).

A common companion of domestic violence is the misappropriation of the spouse's property so that she is economically crippled into subjugation. According to Indian Panel Code if the husband or his relative dishonestly misappropriates or converts to his own use of any property, which the wife has entrusted him with, he is liable for the offence of criminal breach of trust.

As per the National Crime Record Bureau, 2014 Tripura reported the highest rate of crime against women at 88.0 percent and ranked the fourth in India. The statistics of Tripura for last six years admitted that the crime influx against women really happened undoubtedly.

Table 1 reflected that in 2011 there were 1503 cases that were registered while the number went up to 1650 in 2012 and 1706 in 2013 and 1615 in 2014. The statistic shows that the violence against women is increasing nowadays. The crime trend is basically moves or rises against women (NCRB, 2013).

\section{Theories of Domestic Violence}

Violent behaviour is often caused by an interaction of situational and individual factors. An analysis of various types of violence against women and their varied patterns calls for examining the important theories pertaining to domestic violence.

1) Feminist Theory: In the feminist view, batterers feel that they should be in charge of the family: making decisions, laying down rules, disciplining disobedient wives and children, and correcting unsatisfactory performance of duties (Browne et al., 1996). Batterers may typically exercise control over the family in non-violent, coercive ways and only sometimes resort to violence. As men, batterers feel entitled to gender-based respect and obedience; therefore, what they perceive to be disrespect and disobedience infuriates them. Batterers often 
Table 1. Crime chart against women of last Six years.

\begin{tabular}{|c|c|c|c|c|c|c|}
\hline \multirow{2}{*}{ Crime } & \multicolumn{6}{|c|}{ Year } \\
\hline & 2009 & 2010 & 2011 & 2012 & 2013 & 2014 \\
\hline Rape & 209 & 238 & 205 & 229 & 234 & 245 \\
\hline Sexual Harassment & 384 & 376 & 294 & 314 & 407 & 526 \\
\hline Kidnapping & 92 & 91 & 116 & 114 & 124 & 23 \\
\hline Dowry Death & 29 & 25 & 30 & 31 & 28 & 33 \\
\hline Others & 103 & 102 & 122 & 101 & 102 & 109 \\
\hline Total & 1618 & 1778 & 1503 & 1650 & 1706 & 1615 \\
\hline
\end{tabular}

Source: Tripura Commission for Women, 2014.

rationalize their violence on the grounds that it was necessitated by their partner's actions: she provoked or caused it, and they simply reacted as any man would.

2) The Family Systems Theory: Family systems theorists believe that most abuse is verbal and emotional, but as the conflict escalates, either partner may resort to violence. Because, from this perspective, interactions produce violence, no one is considered to be the perpetrator or victim, even if only one person is physically violent. Family systems theory also suggests that interactions may permit or facilitate abusive behaviours in one person, such as a non-abusive parent's failure to intervene in child abuse or a family member's failure to establish appropriate personal boundaries, thus setting the stage for their own victimization.

3) Psychological Theory: Psychological perspectives hold that personality disorders or early experiences of trauma predispose some individuals to violence (Russell, 1988). Being physically abusive is seen as a symptom of an underlying emotional problem.

4) Physiological Theory: Another theory emphasizing on individual is physiological theory. There are several variants of physiological theory. One focuses on evolution and the genetic characteristic that predispose men to violence. Others emphasize brain structures, chemical imbalances, dietary deficiencies and hormonal factors such as testosterone. Genetic and hormonal explanations offer reasons for the greater pre-disposition towards violence in men than in women, but this does not apply to chemical imbalances or dietary deficiencies.

5) Psycho-pathological Theory: The psycho-pathological model focuses on the personality characteristics of offenders and victims as chief determinants of criminal violence. According to the other, violence against women arises out of psychological problems of victims. The socio-psychological model assumes that criminal violence can best be understood by careful examination of external environmental factors that exercise impact on an individual offender.

6) Frustration-Aggression Theory: This theory first stated in 1939 by Dollard et al., derived many of its basic postulates from Freudian theory. It explains the process by which aggression is directed to the source of frustration. When something interferes with an individuals attempt to reach some goal or end, he feels frustrated and frustration in turn leads to some form of aggression (John Dollard). After taking various criticisms into account, this theory was modified. Today it is recognized that an actual display of aggression may be inhibited by either internalized norms of external controls, even though the impulse for aggression may be strong following some frustrating experience. It is also recognized that frustrations can be cumulative and that they can remain active over a long period of time. It is also acknowledged that people perceive frustrations in varying ways, with those deemed arbitrary or unreasonable most likely to trigger aggressive responses. Further, it is recognized that responses to frustrations can be learned. In short, aggressive actions are not an automatic consequence of frustrations, and their occurrence depends upon numerous factors (Ahuja, 1998).

7) Perversion Theory: The psychoanalysts explain violence on the basis of the Theory of Perversion (Giles Pie, 1952) and the Theory of Symptom Formation. They do not regard perverts as constitutionally inferior people but maintain that perversion develops from instincts. According to Freud's early theory (1949), perversion essentially means persistence in the adult infantile instincts and behaviour at the expense of adult behaviour.

8) Self-Attitude Theory: This theory maintains that in a society, a culture, or a group that values violence, persons of low self-esteem may seek to bolster their image in the eyes of others and themselves by carrying out 
violent acts. It explains the propensity to violence of those for whom society makes it difficult to achieve an adequate level of self-esteem.

9) The Cycle Theory: The cycle theory of violence comprises three distinct phases in the cycle of violencethe tension building stage, the acute battering incident and kindness and contrite loving behaviour. In the first stage, when minor battering incidents occur, the woman adapts, rationalizes and externalizes the problem. Tension mounts in the second phase leading to the acute battering incident leading to severe repercussions on the woman physically, emotionally and psychologically. Phase three is welcomed by both the partners, which is marked by uncontrolled love, affection and promises by the husband never to repeat the incidents again (Subadra, 1999).

10) Survivor Theory: As opposed to the cycle theory, E.W. Gondolf and E.R. Fisher proposed the survivor theory in 1988 which views women not merely as passive victims but proactive help-seekers and survivors. The survivor theory credits women with the capacity to innovate newer strategies of coping and acknowledges the efforts of the survivors in seeking help from formal and informal sources. In addition, the survivor theory stresses the need for accessible and effective community resources for the woman to escape from the batterers.

11) Structural Theory: This theory asserts that social groups differ in respect to their typical levels of stress, deprivation and frustration and in the sources at their disposal to deal with these stresses. It explains that those individuals would be more violence who combines high stress with low resources. This theory thus explains an individual's action in terms of the ways it is shaped or determined by social forces of one kind or another. Men and women are socialized into particular roles to which are attached a set of socially determined expectations. If structural faction prevents these expectations from being realized, frustration results and violence may ensue.

12) System Tension and Feedback Systems Theory: This theory was developed by Straus to explain intrafamily violence. Straus accounts for violence in the home by viewing family as a purposive goal-seeking, adaptive social system. According to this theory, violence is precipitated by factors such as stress and inter-individual conflict and is followed by consequences which maintain or escalate violence in family and in society.

13) Resource Theory: Violence is one of the resources that individuals or collective use to maintain or advance their interests. But violence is used as a last resort when all other resources are exhausted. Applying this set of assumptions to the family, Goode explains that family is a power system in which four sets of resources are in operation to maintain stability, economic variables, prestige or respect, love, and force or threat of force.

14) Patriarchy Theory: This theory developed by Dobash and Dobash (1979) maintains that throughout history, violence has been systematically directed towards women. Economic and social processes operate directly and indirectly to support a patriarchal social order and family structure. Dobash's central theoretical argument is that patriarchy leads to the subordination of women and contributes to a historical pattern of systematic violence directed against females.

15) Conflict and Control Theories: The agents of control belong to the dominant group; an overall system of devaluation of the powerless groups (women) can easily be implemented. Schur (1983) contends that male control of deviance levelling results in their continued dominance in most spheres of life.

The constraints on women's rights can be interpreted as function of the successful definition of women as different from and inferior to men. Man talks of woman not in herself but as relative to him. She is not regarded as an autonomous being. She is differentiated with reference to man and not with reference to her. She is the incidental, the inessential as opposed to the essential. Sex role norms clearly differentiate men from women. When these norms become internalized, they are accepted as facts and seldom questioned. Millet (1970) has said: "Because of our social circumstances, male and female are really two cultures and their life experiences are utterly different."

16) Interactionist Deviance Theory: According to the prevalent sex role norms, a husband expects a "good wife" to behave in a certain manner. She has to run the household smoothly, ensure children's well-mannered behaviour, avoid assertiveness of remain submissive to elders in family. Any show of independence on her part would violate sex role expectations for female behaviour. According to deviance theory, norm violations tend to trigger forces aimed at making the violator conform to expected standards of behaviour. Thus, when women do not behave like the male's ideal of wife, husbands use violence against them to make them conform to norms (Ahuja, 1998).

17) Social Learning Theory: Social learning theory while still concentrating on individual perpetrators, introduces a social element by attempting to explain men's violence towards women as learned behaviour (Sharma, 1997).This theory asserts that human aggression and violence are learned conduct, especially through direct ex- 
perience and by observing the behaviour of others. This theory explains both the variations of persons and situations in their tendency to respond aggressive by reference to prior experience, reinforcement patterns and cognitive processes. Steele and Pollock (1974) and Bennie and Sclare (1969) have maintained that abusive male adults are likely to have been raised in abusive homes. In fact, this "family determinism" approach maintains that all victims of childhood violence will grow up to be violent adults (Ahuja, 1977).

18) Cognitive Behaviour Theory: The cognitive behaviour theory postulates that men batter because:

$>$ they are imitating examples of abuse they have witnessed during childhood or in the media;

$>$ abuse is rewarded;

$>$ it enables the batterer to get what he wants;

$>$ abuse is reinforced through victim compliance and submission.

19) Exchange Theory: This theory explains the growth of resentment, anger, hostility and violence when the principle of distributive justice is violated. In applying the principles of the Exchange Theory to explain violence in a family (in our case wife beating, dowry death and rape by family member), we expect that people will use violence in a family if the costs of being violent do not out-weigh the rewards. Goode suggests that force is used more by those in the poorer classes partly because they have less alternative resources and partly because their socialization experiences teach them to depend more on force.

20) Integrated Approach Theory: An attempt has been made by Dr. Ram Ahuja (1998) to develop a theoretical model which would explain all types of violence against women. He describes this middle-range theoretical proposition. This approach has been adopted by borrowing certain concepts from sociologists and criminologists like Hirschi (1976), Schultz (1964), etc. It not only explains the etiologic of violence against women but also uncovers the recurring patterns in which particular types of people are found to commit a particular type of crime against a particular type of individuals, in particular type of circumstances.

This view focuses attention not only on the aggressive act itself but also on the person who uses aggression and the person against whom aggression is used. The man who assaults a woman, physically or mentally, is often the man who either feels at a disadvantage with women or who feels at an advantageous position in demanding a specific thing from a woman.

21) The Multi-Factorial Systemic Theory: This theory was propounded by Bhatti and Beig (1985). "Within the multi-factorial and systemic model, family violence can be defined as action performed by a family member to get the desired conformity from the other members and when it carries a negative emotional component”.

The acts of violence seen in underdeveloped societies may be more physical in nature while families in the developing countries may exhibit violence in emotional and intellectual areas. The relative degree of violence and the type of violence will therefore, depend on the developmental phase of the society.

As per the above mentioned different theories of violence various factors are responsible for violence against women. Violence against women includes headship pattern of family, family conflicts, psychological trauma, physiological factors like genetic, hormonal, etc., personal characteristics, different social factors are responsible. Though different theories define different factors but some common factors of domestic violence are described below.

22) Factors of Domestic Violence: Violence against women and girls is a worldwide phenomenon which spans all social classes and age groups. The main cause is the power gap between men and women and the way women are disadvantaged in key areas. Relations between men and women are closing bound up with political and economic structures. Majority of the poor worldwide are female. They generally less than men and are forced into marginal sectors of the labour market with a lower economic status. They are less likely to have access to education and carrier development and are less involved in political decision making process. Violent behaviour is not biologically predetermined. Rather, it is acquired as a result of gender-specific socialization. In many societies, for instance, physical strengths, aggressive behaviour and threatening gestures in male children and young men are approved and fostered as positive qualities. Girls, on the other hand, are brought up to be compliant and considerate.

Table 2 describes the violence visible through out the life cycle of women. Women's movements have reshaped the world's democracies, demanding that governments and citizens pay attention to "women's issues” such as pay equity, violence, feminization of poverty, reproductive rights, and representation. But women's movements, like many contemporary social movements, are increasingly divided along lines of race, sexuality, ethnicity, and class. When such division obstructs cooperation; women lose their most effective advocates in the public sphere. With a renewed assault on women's reproductive rights, economic security, and freedom from 
Table 2. Examples of gender based violence visible at different stages throughout the life cycle.

\begin{tabular}{|c|c|}
\hline Prenatal & $\begin{array}{l}\text { Pre Birth elimination of female } \\
\text { Physical battery during pregnancy }\end{array}$ \\
\hline \multirow{6}{*}{ Infancy } & Female infanticides \\
\hline & Differential access to care, nutrition, healthcare, education \\
\hline & Child marriage \\
\hline & Child sexual abuse \\
\hline & Child Prostitution \\
\hline & Differential access to care, nutrition, healthcare, education \\
\hline \multirow{9}{*}{ Adolescence } & Molestation/eve teasing \\
\hline & Rape \\
\hline & Incest \\
\hline & Sexual Harassment in the work place \\
\hline & Forced Prostitution \\
\hline & Trafficking \\
\hline & Violence associated with premarital pregnancy, abortion \\
\hline & Differential access to care, nutrition, healthcare, education \\
\hline & Kidnapping and abduction \\
\hline \multirow{9}{*}{ Youth and Adulthood } & Domestic Violence \\
\hline & Marital Rape \\
\hline & Dowry related abuse and murder \\
\hline & Coerced pregnancy \\
\hline & Homicide \\
\hline & Sexual Harassment in the work place \\
\hline & Molestation/eve teasing, sexual abuse \\
\hline & Differential access to care, nutrition, healthcare, education \\
\hline & Desertion \\
\hline \multirow{4}{*}{ Old Age } & Abuse of the elderly (forms affecting women more than men) \\
\hline & Abuse of widows \\
\hline & Threat of sexual violence \\
\hline & Lack of access to care, nutrition and medical facilities \\
\hline
\end{tabular}

Source: ICRW, 2004.

violence in the United States and around the world, women need effective sources of policy influence more than ever. It is critical, then, that movements overcome these divisions and improve their influence on policy and society (S. Laurel Weldon (2006) Inclusion, Solidarity, and Social Movements: The Global Movement against Gender Violence, Published by: American Political Science Association, Perspectives on Politics, Vol. 4, No. 1, pp. 55-74).

\section{Domestic Violence against Women in India}

After prevention of Domestic Violence Act, 2006 ten thousands domestic violence cases by major states in India are reported against women during 2006-07 is represented in below mentioned table and it is also importance to state that maximum cases depart unreported. 
Table 3 surprisingly shows that major states of India have maximum number of recorded cases of domestic violence after the implementation of domestic violence Act. The literacy rate of Kerala is better then Rajasthan but Kerala placed second position in the country. Education is a crucial factor for domestic violence, the above mentioned table reveals that high literacy rate may the level of awareness is high so the number of recorded cases are also. In case of Rajasthan less literacy rate results lack of awareness and more number of register and non registered cases of domestic violence.

National Commission for Women has in 2003-04 recorded 902 cases of dowry harassment and 310 cases of matrimonial disputes. The National Crime Record Bureau (NCRB) Report 2003 indicates that 36.1 per cent of the total reported crimes against women pertain to domestic violence.

Domestic violence leads to violence of human rights and prevents them from enjoy their fundamental rights. Violence against women is not an answer. It is a problem, one that is increasingly on the rise. Gender Violence has some definite effects for our civil society, which may occur due to some reasons.

i) Poverty: Poverty is reported as the most profound background risk factor for violence against children and women (Bethea, 1999; WHO, 2002). It is common myth that domestic Violence only happens to poor women, in fact it occurs in all kinds of families and relationships. Poverty has been identified as both a contributing factor and as a consequence for interpersonal violence (WHO, 2004). Low economic status of the household is not necessarily a casual factor; it is generally assumed to significantly increase the risk of domestic violence (Ghosh 2007).

ii) Locality: A multinational study based on prevalence and incidence of domestic violence in developing world, six out of none countries showed women living in urban areas are significantly more likely to report domestic violence than rural women, on the other only two countries India and Egypt showed reciprocal relationship (Kishore, 2004). Locality is another dominating factor for domestic violence in Tripura. Rural victims are more suffers than to the urban ones from domestic violence and number cases are higher in rural Tripura (Roy, 2010).

iii) Educational level: Level of education is one of the determining factors in case of Domestic violence and relationship status. As per the multinational study based on prevalence and incidence of domestic violence it can be hypothesized that the relation between husband's education and violence is negative and monotonic (Kishor,

Table 3. State-Wise domestic violence cases and literacy rate.

\begin{tabular}{ccc}
\hline State & No. of Cases & Literacy Rate \\
\hline Rajasthan & 3440 & $67.10 \%$ \\
Kerala & 1028 & $87.89 \%$ \\
Andhra Pradesh & 331 & $91 \%$ \\
Delhi & 607 & $86.3 \%$ \\
Maharashtra & 603 & $80.1 \%$ \\
Goa & 603 & $82 \%$ \\
Gujarat & 315 & $77.3 \%$ \\
Punjab & 249 & $79.7 \%$ \\
Haryana & 235 & $76.6 \%$ \\
Uttaranchal & 145 & $79.6 \%$ \\
Karnataka & 124 & $75.6 \%$ \\
Bihar & 64 & $63.8 \%$ \\
West Bengal & 12 & $77.1 \%$ \\
Orissa & 1087 & $73.45 \%$ \\
Other states & 54 & - \\
\hline
\end{tabular}

Source: According to Indira Jai Singh, Lawyers Collective (till July, 2007) and Census, 2011. 
2004). In case of husband if the education is higher mental torture is also higher and with the less education physical torture is elevated. The study conducted by the Northeast Network (NEN, 2004) in the North Eastern States like in Manipur and Assam regarding "Violence against Women in North East India", 2004 cited that gender based violence is on the rise due to lack of societal support of women, lack of knowledge of right and gender insensitivity issue. The present study found that if the education status of wife is higher than the mental violence is higher than to the physical and sexual.

iv) Economic share: It is quite natural that economically independent women i.e. women participating in economic activities are able to contribute financially in the family and that's why may be expected to be less likely to be victimized to domestic violence. As per NFHS III, employed women experienced higher rates of physical as well as mental violence. According to the study conducted by TWC, 2005-06 on "Land right of Women in Tripura” (The Tripura Commission for Women, 2006) denoted that in poor families land ownership of women was very less and maximum land owning women were educated. Where as it was found that in Muslim religion women was less in percentage, who had owned land. So, the dependency ratio is one of the indicators of violence. It's seems that economically empowered women are less victim of any kind of violence.

v) Decision making: The power of decision making in a family indicates that the family culture. If the family depends on the decision of women members of the family, it reflects family members have enough faith on her. Hence, it is usually considered as an indicator of women empowerment. Empowered women are naturally less prone to domestic violence. Ironically it is found that if the female contributes more in the family earning or economically sounds enough have more power decision making, reveals that economic capacity of a women has definite co-relation with her decision making in family matters. As per Roy, 2010 decision making regards monetary, expenditure, family planning and others mainly taken by the male counter part of the family.

vi) Dowry: As per Dowry Prohibition Act both taking and giving dowry are considered as criminal offence. In spite of this Act in sections of the society taking and giving of dowry occurred frequently. It is seems that prevalence of different types of domestic violence is higher in those families who had taken dowry during marriage than those who not taken. As per the news daily the North East Today 544 nos dowry death had been recorded till January, 2015 for the FY 2014-15, which is really very painful. So it may revealed that dowry related crime, violence even death are prevailing in the society.

Figure 1 shows the dowry death trend of last 3years of Tripura and occurrences.

vii) Age at Marriage: Age at marriage is a reflection of status of women, at the contextual level (Mason, 1987). A women's young age at first union is generally thought to be another risk factor for the experience of domestic violence (Kishor, 2004). The study on 'Domestic Violence against Women in Tripura: A Case study on North Tripura District' also reveals that prevalence of different types of violence or incidence of domestic violence highest when the age of the female partner is below 18 years and declined with the increased in age of marriage of the wife (Roy, 2010).

viii) Different Addiction of Husband: Addiction of husband found to be another crucial factor of Domestic violence results higher physical and sexual violence to women. Alcoholism of husband and husband living constantly under tension due to problems at work place is another crucial reason of violence. The study of Roy (2010) admitted that 67 percent respondents agreed that husbands were addicted to liquor and ganja etc.

So these are some common factors of domestic violence, which are also prevailing in Tripura. In order to pro-

\section{No.of Dowry Death}

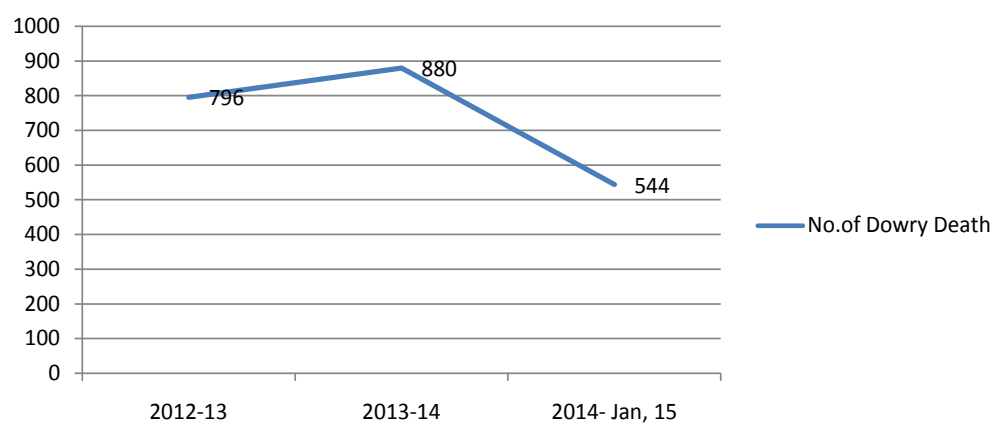

Figure 1. Dowry death in Tripura for last 3 yrs. 
vide maximum possible support to the women in distress amidst the high trend of crime against women across the state, Tripura police on the occasion of international women's day on $8^{\text {th }}$ March, 2014 at Agartala launched a helpline (1091) for women, which will work round clock. Counselling of women will also be provided through this helpline, in case of necessity.

The analysis of research findings of various surveys and studies show that there is increasing trend of domestic violence against women. There are various socio-cultural and economic determinants of domestic violence while the nature and forms of domestic violence vary from society to society depending upon socio-economic and cultural status of the societies. There are also marked variations in the nature, extent and impact of domestic violence against women across the geographical regions of India. In India, the actual prevalence of domestic violence against women is scant. Moreover, it simply demonstrates that a large proportion of women belonging to lower caste and communities experience domestic violence. Moreover, physical violence is more pronouncing in the lower classes of the society. The domestic violence is mainly reported in form of emotional violence; however, nature and frequency of domestic violence vary depending upon the socio-cultural variables. The main reasons of domestic violence are related to economic spheres; however, other social factors also influence the nature and frequency of domestic violence.

\section{Recommendations}

With the prevailing status of domestic violence in Tripura and after analyzing the facts and figures of the different sources, the recommendations are given below:

- Prevalence of domestic violence can be reduced through awareness generation and sensitization of different stakeholders like Judiciary, Government, Police personnel, NGOs, Health care support provider, counsellors, service provider and protection officers by creating a strong network among them.

- Education, which is a very strong factor of planned social change, can accelerate the process of change in attitudes and thereby in behaviours of males towards females. Formal and non-formal education along with the frequent appeals on non objectification and non commercialization of women in mass media can play a vital role in decreasing the violence against women in India.

- Collaboration among different Government agencies and NGOs should be encouraged in order to prevent duplication of services, ensure better utilization of scarce resources, and increase the information dissemination. Social network support, especially the natal family and neighbors, is also crucial in reducing domestic violence. Support structures could be from both contexts within the family and from NGOs, women's Self Help Groups.

- Creation of crisis referral services is also needed like women helpline of Tripura Police. The local helpline or crisis referral services can take calls from women or family members or concerned neighbors regarding incidence of any violence and enquiry about legal, medical or psychological services. The government should implement projects, programmes to encourage community driven initiatives to address the needs of the victims of gender based violence.

- Existing preventive and supporting programme interventions also need to be expanded for the victims of gender based violence. While attempts should be made to strengthen women's economic capabilities by improving women's access and control over income and assets.

\section{References}

Ahuja, R. (1998) Violence against Women. Jaipur: Rawat Publications.

Bhatti, R. S., \& Beigh, M. A. (1985). Family Violence: A Systemic Model. Indian Journal of Social Psychiatry, 1, $174-185$.

Browne, K., Saunders, D. G., \& Staecker, K. M. (1996). Process-Psychodynamic Groups for Men Who Batter: Description of a Brief Treatment Model. Ann Arbor, MI: University of Michigan.

Coomarswamy, R. (2005). Human Security \& Gender Violence. Economic \& Political Weekly, October 29, 2005.

Ghosh, S., \& Mohanty, S. K. (2007). Domestic Violence \& Reproductive Health Among Young Married Women in India: An Exploration from NFHS-II. IUSSP Conference Tours, France, 18-23 July 2007, 192-195.

International Institute for Population Sciences (2007). Report of National Family Health Survey-III. Mumbai: International Institute for Population Sciences.

Mukherjee, C. et al. (2001). Crimes against Women in India: Analysis of Official Statistics. Economic \& Political Weekly, October 27, 2001. 
NCRB (2013). National Crime Report Bureau. http://www.ncrb.gov.in/

Roy, M. (2010). Domestic Violence against Women in Tripura. Agartala: Tripura Commission for Women.

Russell, M. (1988). Wife Assault Theory, Research, and Treatment: A Literature Review. Journal of Family Violence, 3, 193-208. http://dx.doi.org/10.1007/BF00988975

Singh, A. P. (2013). Domestic Violence in India: A Study of Prevalance. In A.K Singh, S. P. Singh, \& S. K. Biswas (Eds.), Nature and Impact, Gender Violence in India: Perspective, Issues and Way Forward (pp. 84). New Delhi: Bal Vikas Prakashan.

The Northeast Network (2004). Violence against Women in North East India: An Enquiry. New Delhi: The Northeast Network.

The Tripura Commission for Women (2006). Land Rights of Women in Tripura: A Monograph Based on a Research Study. New Delhi: The Tripura Commission for Women.

Weldon, S. L. (2006). Inclusion, Solidarity, and Social Movements: The Global Movement against Gender Violence. Perspectives on Politics, 4, 55-74. http://dx.doi.org/10.1017/S1537592706060063

WHO (2002). World Report on Violence and Health. Geneva: World Health Organization.

WHO (2004). World Report on Violence and Health. Geneva: World Health Organization. 